\title{
Consumption of low-fat dairy foods for 6 months improves insulin resistance without adversely affecting lipids or bodyweight in healthy adults: a randomized free-living cross-over study
}

Todd C Rideout ${ }^{1{ }^{*}}$, Christopher P F Marinangeli ${ }^{2+}{ }$, Heather Martin ${ }^{2}$, Richard W Browne ${ }^{3}$ and Curtis B Rempel ${ }^{2^{*}}$

\begin{abstract}
Background: Given the highly debated role of dairy food consumption in modulating biomarkers of metabolic syndrome, this study was conducted to examine the influence of long-term (6 month) dairy consumption on metabolic parameters in healthy volunteers under free-living conditions without energy restriction.

Methods: Twenty-three healthy subjects completed a randomized, crossover trial of 12 months. Participants consumed their habitual diets and were randomly assigned to one of two treatment groups: a high dairy supplemented group instructed to consume 4 servings of dairy per day (HD); or a low dairy supplemented group limited to no more than 2 servings of dairy per day (LD). Baseline, midpoint, and endpoint metabolic responses were examined.

Results: Endpoint measurements of body weight and composition, energy expenditure, blood pressure, blood glucose, and blood lipid and lipoprotein responses did not differ $(p>0.05)$ between the LD and HD groups. HD consumption improved $(p<0.05)$ plasma insulin $(-9 \%)$ and insulin resistance $(-11 \%, p=0.03)$ as estimated by HOMA-IR compared with the LD group.

Conclusions: Study results suggest that high dairy consumption (4 servings/d) may improve insulin resistance without negatively impacting bodyweight or lipid status under free-living conditions.
\end{abstract}

Trial registration: Clinical Trials.gov: NCT01761955

Keywords: Dairy, Glucose, Insulin, Lipids, Bodyweight

\section{Background}

Dairy has been an important component of the human diet, mainly valued for its superior amino acid composition, high protein quality, and a source of calcium [1]. Beyond it's macronutrient composition, low fat dairy foods contain an array of health promoting bioactive components including whey peptides, conjugated linoleic acid, sphingolipids, oligosaccharides, and imunoglobulins [2].

\footnotetext{
* Correspondence: rideout@buffalo.edu; rempelc@canolacouncil.org ${ }^{\dagger}$ Equal contributors

'Department of Exercise and Nutrition Sciences, School of Public Health and Health Professions, University at Buffalo, Buffalo, New York 14214, USA

${ }^{2}$ The Richardson Centre for Functional Foods and Nutraceuticals, University of Manitoba, Winnipeg, Manitoba R3T 2N2, Canada

Full list of author information is available at the end of the article
}

However, despite this rich bioactive composition, the health effects of dairy are highly disputed [3,4].

Increased dairy consumption has been demonstrated to reduce obesity [5] and modulate metabolic disturbances including hyperinsulinemia [6] and blood pressure $[7,8]$. Prospective cohort studies suggest that consumption of low fat dairy products is associated with a low incidence of type 2 diabetes compared with low dairy diets [9-12]. A recent meta-analysis of 7 cohort studies by Tong et al. [11] suggests that increased consumption of total and low fat dairy products may reduce the risk of type 2 diabetes by 5 and $10 \%$, respectively. This disease reduction potential may be linked with the insulin sensitizing properties of dairy products as Ruidavets et al. have reported that high consumption of 
dairy products is associated with a lower probability of insulin resistance (odds ratio 0.67) [13].

Alternatively, it has been suggested that long-term high fat dairy consumption may underlie the pathogenesis of type II diabetes by promoting $\beta$-cell apoptosis [14] and increase CVD risk by contributing to hyperlipidemia. These negative health responses may be linked with increased intake of insulin-like growth factors (1 \& 2) [3] and saturated fat of dairy foods [15-17]. Inconsistent data from different studies on the health benefits of dairy may be attributed to differences in experimental design (study population, health status, ethnicity, and gender) [18] and differential health effects of specific dairy products [19]. Furthermore, it has been suggested that the health promoting effects of increased dairy consumption, particularly with respect to weight loss, may be associated with an energy restricted diet [20]. Additional long-term randomized controlled trials are needed to resolve the current controversies regarding the effects of increased dairy consumption on risk factors for type 2 diabetes, in addition to other metabolic health responses. Therefore, the aim of the present study was to examine the long-term (6 months) effects of high dairy consumption (4 servings per day) on metabolic parameters in healthy volunteers under free-living conditions without energy restriction or other lifestyle modifications. The primary aim of this study was to observe the effect of dairy consumption on metabolic parameters including blood lipids, glucose, and insulin. Secondary endpoints were body weight and composition, and energy expenditure.

\section{Methods}

The study was conducted at the Clinical Nutrition Research Unit at the Richardson Centre for Functional Foods and Nutraceuticals (RCFFN), University of Manitoba between April 2009 - May 2011. Subjects were recruited from the Winnipeg area via newspaper and radio endorsements, poster advertisements, and flyer distributions.

\section{Inclusion/exclusion criteria}

Male and female subjects (18-75 years of age) were eligible for study participation if they had a BMI between $18.5-35.0 \mathrm{~kg} / \mathrm{m}^{2}$ and were assessed to be healthy based on a pre-study screening examination including medical, diet, and lifestyle history. Age and BMI inclusion ranges were wide-ranging in anticipation of difficulty in recruiting subjects for a 1-year intervention. Subjects were excluded if pregnant; diagnosed with diabetes or cardiovascular, liver, or renal disease; reported regular use of appetite suppressants or Orlistat (Xenical) or irregular use of other treatments which might interfere with the outcomes of the study (e.g. anti-hypertensives, statins, thyroxine, omega-3 supplements); reported habitual consumption of more than $1 \frac{1 / 2}{2}$ servings of dairy per day; or were unable to consume 4 servings of low fat dairy per day for 6 months due to known allergy or dairy intolerance. To confirm individual health status and eligibility, all subjects underwent a complete physical examination conducted by the study physician.

\section{Study design and protocol}

The study protocol was approved by the Joint Faculty Research Ethics Board (JFREB) at the University of Manitoba. All subjects signed informed consent to participate in the study.

The study was a randomized, crossover trial of 12 months with no washout period due to the length of each study phase (Figure 1). At the onset of the study, eligible participants $(n=39)$ were instructed to consume their habitual diets and randomly assigned to one of two treatment groups for 6 months using a random number generator: a high dairy supplemented group instructed to consume 4 servings dairy per day (HD); or a low dairy supplemented group limited to no more than 2 serving dairy per day (LD). At the end of the initial 6-month phase, subjects initially randomized to the HD group were switched to the LD treatment and vise versa for the remainder of the study. The LD and HD serving sizes were based on Canada's Food Guide, which recommends 2-3 servings of low fat dairy products per day

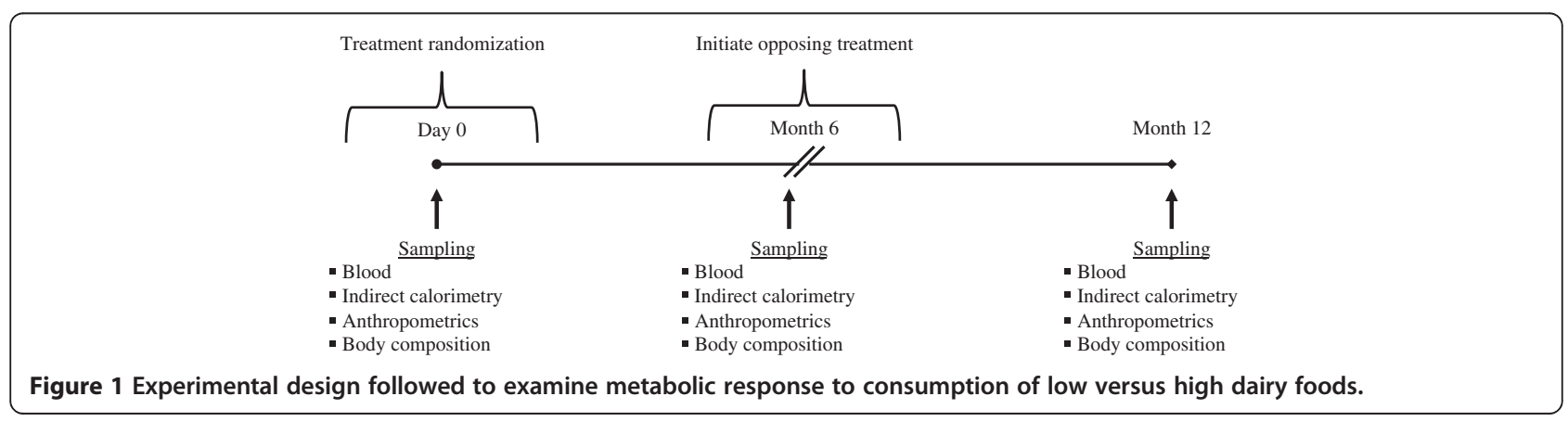


depending on age and sex. However, it has been reported that $65-80 \%$ of Canadian adult consume less than 2 servings per day [21]. Subjects assigned to the HD group were regularly provided (every 2 weeks) with standard servings of low fat dairy products (eg. $250 \mathrm{~mL}$ milk, $175 \mathrm{~g}$ yogurt) for dietary incorporation as indicated in Canada's Food Guide. Subjects were instructed to consume only those dairy products that were provided by the research staff. During the HD phase, subjects were asked to incorporate dairy products into their diets by substitution so as not to increase their normal energy intake. During the LD phase, subjects were instructed to consume their normal diets but to not exceed more than 2 servings of dairy per day. Nutrient composition of the low fat dairy products is presented in Table 1. Subjects were instructed to maintain their normal diet and level of physical activity for the duration of the study periods. Beyond instructions as to how to incorporate dairy into their daily diet, the subjects received no dietary counseling throughout the study period.

\section{Data collection time points}

At two separate points during each phase (4 and 6 months of each intervention phase), subjects were asked to complete a food frequency questionnaire (adapted from the National Institutes of Health Diet History Questionnaire), physical activity diary, and 3-day midweek food record. To monitor compliance, subjects were provided with a logbook and asked to record the number of dairy servings consumed each day. At baseline and the end of each 6-month period, fasting measurements of body weight, blood pressure, DEXA, and indirect calorimetry were obtained. Furthermore, 12-h fasted blood draws were collected for blood biochemistry measurements at baseline, midpoint, and endpoint as outlined in Figure 1. Subject anthropometric and metabolic measurements taken prior to the start of the study are provided in Table 2.

Table 1 Macronutrient composition of low fat milk and yogurt products provided to study subjects

\begin{tabular}{lll}
\hline Macronutrient & Skim milk & \\
\hline Serving size & $250 \mathrm{~mL}$ & Yogurt \\
\hline Energy/serving (kJ) & 370 & $100 \mathrm{~g}$ \\
Carbohydrate (g) & 12.84 & 180.03 \\
$\quad$ Sugar & 13.18 & 6 \\
$\quad$ Fiber & 0 & 6 \\
Protein (g) & 8.72 & 0 \\
Fat (g) & 0.21 & 4 \\
$\quad$ Saturates (g) & 0.156 & 0.08 \\
$\quad$ Trans fat (g) & 0.008 & 0 \\
\hline
\end{tabular}

${ }^{1}$ Provided by Aliments UTLIMA Foods Inc. / Yoplait, Granby, QC.
Table 2 Baseline characteristics of study subjects prior to start of study ${ }^{1}$

\begin{tabular}{ll}
\hline Variable & Mean \pm SD \\
\hline General characteristics & \\
\hline Age (y) & $53 \pm 12.26$ (range 22-72) \\
Gender (M/F) & $5 / 18$ \\
Height (m) & $1.65 \pm 0.08$ \\
Body weight $(\mathrm{kg})$ & $85.61 \pm 10.30$ \\
Body mass index (kg/m2) & $31.86 \pm 3.01$ \\
Waist circumference (cm) & $99.76 \pm 9.83$ \\
Waist:hip & $0.84 \pm 0.07$ \\
Systolic blood pressure & $125.34 \pm 17.90$ \\
Diastolic blood pressure & $77.82 \pm 14.12$ \\
DEXA & \\
\hline Total body fat (\%) & $47.46 \pm 4.51$ \\
Abdominal fat (\%) & $47.36 \pm 8.03$ \\
Lean body mass (\%) & $50.95 \pm 4.64$ \\
Plasma biochemistry & \\
\hline Glucose (mmol/L) & $5.17 \pm 0.68$ \\
Insulin ( $\mu \mathrm{U} / \mathrm{mL})$ & $15.37 \pm 2.80$ \\
Total cholesterol (mmol/L) & $5.73 \pm 0.62$ \\
LDL-cholesterol (mmol/L) & $3.49 \pm 0.57$ \\
HDL-cholesterol (mmol/L) & $1.42 \pm 0.37$ \\
Triglycerides (mmol/L) & $1.79 \pm 0.54$ \\
ApoB (mg/dL) & $85.56 \pm 31.88$ \\
ApoE (mg/dL) & $5.00 \pm 1.66$ \\
Lp(a) (mg/dL) & $52.20 \pm 60.58$ \\
Apocll (mg/dL) & $5.82 \pm 2.57$ \\
\hline Metabolic rate $(\mathrm{kJ} / \mathrm{min})$ & \\
\hline
\end{tabular}

${ }^{1} n=23$ for LD; $n=23$ for HD.

\section{Procedures}

\section{Blood collection and blood pressure}

Twelve-hour fasting serum and plasma blood samples were collected at the beginning and end of each study phase. Blood was centrifuged at $3000 \times g$ for 20 minutes at $4^{\circ} \mathrm{C}$ to separate serum and plasma from erythrocytes, which were then stored at $-20^{\circ} \mathrm{C}$ for future analyses. Resting blood pressure and heart rate (average of two measurements) were recorded by automated oscillometry with the subject in supine position.

\section{Body composition protocol}

Body composition, including percentage of total fat mass (\%TFM), TFM and total lean mass, as well as percentage android and gynoid fat, were assessed at the start and 
end of each study phase using fan beam dual-energy X-ray absorptiometry (LunarProdigy Advance; GE Healthcare, Madison, WI, USA). Body composition data including \%TFM, TFM, and total lean mass were determined using Encore 2005 software version 9.30.044 (GE Healthcare).

\section{Energy expenditure}

At the beginning and end of each study phase, fasting energy expenditure was determined using open circuit indirect calorimetry (Vmax Encore, Summit Technologies Inc, Burlington ON Canada) fitted with a ventilated canopy. The flow sensor and gas sensors were calibrated daily prior to initiating respiratory measurements. The flow sensor was calibrated using a calibration syringe. Gas sensors were automatically calibrated by Vmax Encore software (Cardinal Health, Maple, ON Canada) using two reference gasses with the first containing $16 \%$ $\mathrm{O}_{2}, 4 \% \mathrm{CO}_{2}$ and $80 \% \mathrm{~N}_{2}$ and the second containing 26\% $\mathrm{O}_{2}, 0 \% \mathrm{CO}_{2}$ and $74 \% \mathrm{~N}_{2}$. All indirect calorimetry data was collected using Vmax Encore software. Commencement of pre-menopausal women into the study was planned such that they did not undergo indirect calorimetry measurements during their menstrual cycle. Indirect calorimetry measurements were taken for $30 \mathrm{~min}$. The first $15 \mathrm{~min}$ acted as a stabilization period, while data from the latter $15 \mathrm{~min}$ was used to determine fasting energy expenditure, fat oxidation and carbohydrate oxidation. The methodologies used to calculate these measures are discussed elsewhere [22]. As subjects were fasting, the constant $0.829 \mathrm{~L} \mathrm{O}_{2} / \mathrm{g}$ glycogen was used to calculate carbohydrate oxidation $[23,24]$.

\section{Blood biochemistry analyses}

Plasma total cholesterol (TC), high-density lipoprotein cholesterol (HDL-C), triglycerides (TG), and glucose were determined by automated enzymatic methods on a Vitros 350 chemistry analyzer (Ortho-Clinical Diagnostics, Markham, Ontario, Canada). LDL-C concentrations were estimated by the difference method using the Friedewald formula. Apolipoproteins were measured by immunoturbidometric assay on a Pentra 400 autoanalyzer according to manufacturer's instructions (Kamiya Biomedical Company, Seattle, WA, USA; kits: ApoB, KAI-004; ApoE KAI-007; CII, KAI-005; Lp (a), KAI-044). Serum insulin was analysed by ELISA (EZHIASF-14K, Millipore, Billerica, MA). Insulin homeostasis modeling assessment (HOMA) was utilized as an estimate for insulin resistance (IR). HOMA values were calculated using previously outlined methods [25].

\section{Statistical analysis}

The study was powered based on previously reported lipid responses following 21 weeks of high dairy consumption [26,27]. A sample size of 20 subjects was anticipated to detect a $19 \%$ reduction in blood TG (alpha $0.05 ; 0.80$ power). In anticipation of a large dropout rate due to the long study duration, 39 subjects were recruited to begin the trial. Data were analyzed with a linear mixed model ANOVA with subject as a random factor. Baseline measurements of each phase were used as covariates for endpoint measurements. Data were further analyzed as percent change from baseline responses for LD vs. HD phases. Macronutrient intake data collected from mid-week 3-day food records were analyzed with Food processor (Food processor, Salem, OR). All data are presented as means \pm SD and statistical significance was set at $\mathrm{p}<0.05$ for all analyses. Data were analyzed using IBM SPSS software version 19.0 (SPSS, Inc., Chicago, IL, USA).

\section{Results}

One hundred and forty-four individuals initially responded to the recruitment strategy that focused on dairy as a diet intervention for improvement of cardiometabolic risk factors. Of these 144 respondents, 51 individuals were screened and deemed eligible for the trial, and 39 subjects agreed to participate. Of the initial 39 subjects that began the study, 23 completed both study phases ( $\mathrm{n}=23$ for both LD and HD). Subjects provided several reasons for dropping out of the study including an inability to consume the required daily amount of dairy $(\mathrm{n}=2)$, personal family obligations $(\mathrm{n}=$ $13)$, and relocation $(n=1)$ (Figure 2). Baseline characteristics of dropout subjects were not different $(p>0.05)$ than those who completed the study (data not shown).

Macronutrient intake during the two periods did not differ $(p>0.05)$ between the LD and HD groups (Table 3). Calcium intake in the HD group tended to be higher $(\mathrm{p}=0.10)$ than the LD group whereas there was no difference $(p>0.05)$ in vitamin $D$ intake between groups (Table 3).

Endpoint and percent change adjusted whole-body and metabolic responses between the LD and HD phases are presented in Table 4. Although no difference $(p>0.05)$ was observed in blood glucose between the LD and HD groups, HD consumption reduced $(p<0.05)$ plasma insulin and improved $(p<0.05)$ insulin resistance as estimated by HOMA-IR, (endpoint and percent change Table 4). Endpoint and percent change variables in body weight and body composition, energy expenditure, blood pressure, and blood lipid and lipoprotein responses did not differ $(p>0.05)$ between the LD and HD phases.

\section{Discussion}

The major finding of this study is that consumption of 4 servings/d of low-fat dairy milk and yogurt products under free-living conditions for 6 months reduced 


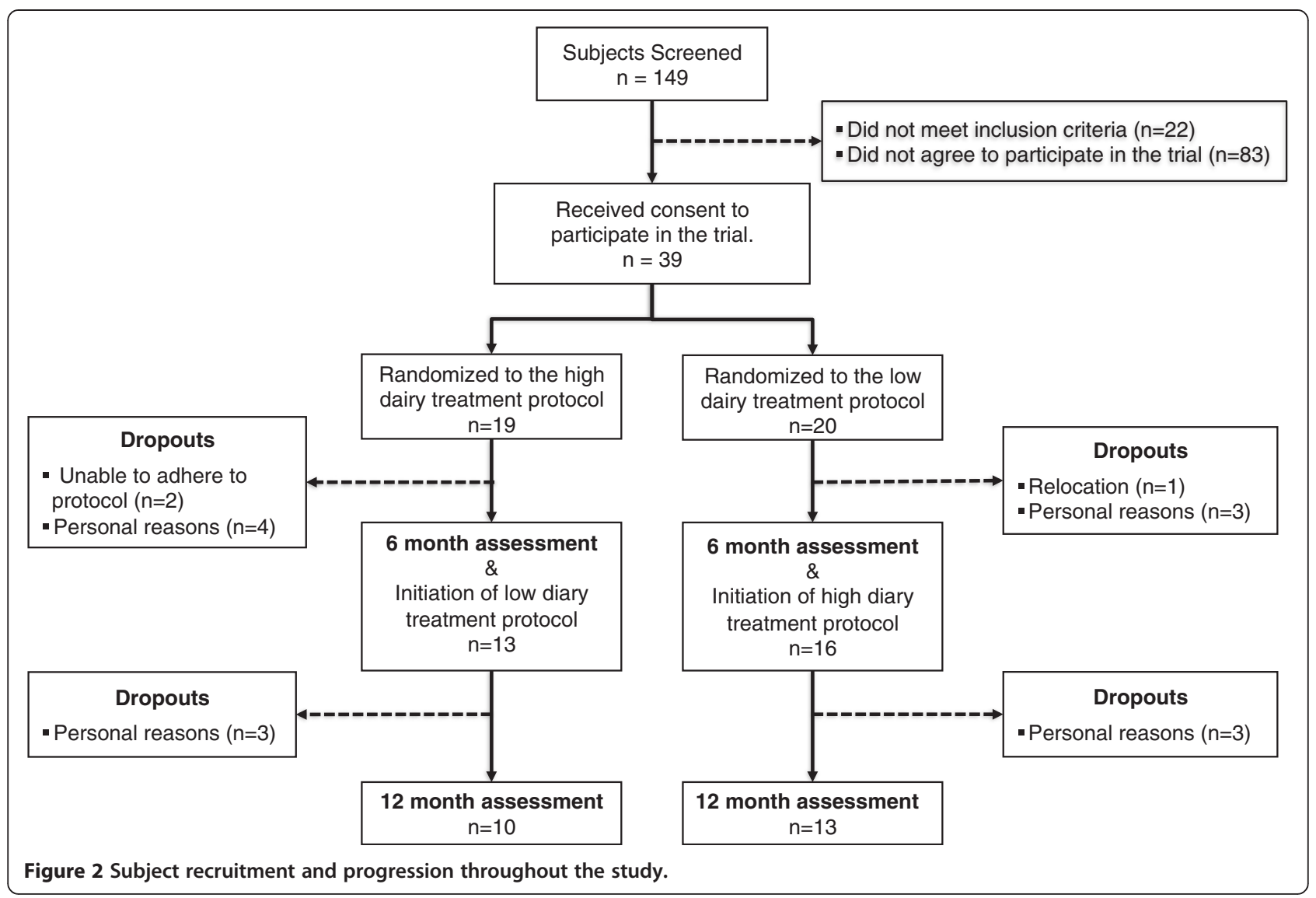

Table 3 Selected daily nutrient intake estimated from 3-day mid-week food records ${ }^{1}$

\begin{tabular}{lll}
\hline Item & Low dairy & High dairy $^{\mathbf{2}}$ \\
\hline Total calories & $2396 \pm 430$ & $2268 \pm 502$ \\
Carbohydrate (\% energy) & $51.08 \pm 6.93$ & $54.13 \pm 6.71$ \\
Fat (\% energy) & $34.06 \pm 5.72$ & $30.07 \pm 4.75$ \\
Protein (\% energy) & $15.98 \pm 3.29$ & $15.81 \pm 1.74$ \\
Total Carbohydrates (g) & $299.66 \pm 139.38$ & $307.65 \pm 83.07$ \\
Monosaccharides (g) & $13.54 \pm 10.11$ & $10.87 \pm 8.03$ \\
Disaccharides (g) & $13.48 \pm 4.76$ & $8.92 \pm 3.15$ \\
Total dietary fiber (g) & $25.58 \pm 9.04$ & $23.79 \pm 8.41$ \\
Total Fat (g) & $94.55 \pm 38.12$ & $76.09 \pm 22.08$ \\
Saturated fat (g) & $26.72 \pm 9.44$ & $24.1 \pm 8.52$ \\
Monounsaturated fat (g) & $19.55 \pm 9.97$ & $15.06 \pm 7.96$ \\
Polyunsaturated fat (g) & $9.55 \pm 3.37$ & $8.74 \pm 3.09$ \\
Cholesterol (mg) & $273.29 \pm 96.62$ & $217.87 \pm 77.03$ \\
Total Protein (g) & $94.32 \pm 42.83$ & $88.14 \pm 31.16$ \\
Vitamin D ( $\mu$ g) & $4.77 \pm 1.68$ & $6.17 \pm 2.18$ \\
Calcium (mg) & $1024.31 \pm 347.77$ & $1222 \pm 163.15$ \\
\hline Estmated from & &
\end{tabular}

${ }^{1}$ Estimated from 3-day food records taken at 4 and 6 months of each intervention phase.

${ }^{2}$ Mean $\pm S D ; n=23$. fasting plasma insulin (9\%) and improved insulin resistance $(11 \%)$ in overweight and obese adults. Although the long-term clinical implications of these results are unclear, fasting insulin and HOMA-IR have been shown to be sensitive predictive markers of diabetes, ischemic stroke, and coronary heart disease risk in the general population as well as in at-risk subjects [28-32]. Previous data from the Verona Diabetes Complications Study suggest that every 1-unit increase in HOMA-IR is associated with an odds ratio of CVD incidence of 1.56 in Type II diabetics [33]. This improvement in insulin resistance may be protective in this population of overweight and obese individuals.

Our results are supported by dairy intervention studies under both controlled feeding and free-living conditions. Compared to a low dairy diet $(<0.5$ servings/d), a 12week study by Stancliffe et al. (2011) reported reductions in fasting insulin and insulin resistance in a similar population of overweight and obese subjects consuming dairy as milk and yogurt (3.5 serving/d) [6]. Similar results were recently reported by Nikooyeh et al. (2011) [34] in type 2 diabetics consuming $250 \mathrm{~mL} /$ day of plain, vitamin $\mathrm{D}$-fortified, or a vitamin $\mathrm{D}+$ calcium-fortified yogurt drink. Moreover, results from a recent metaanalysis and previous observational and prospective 
Table 4 Metabolic parameters at the end of the 6 month low and high dairy phases

\begin{tabular}{|c|c|c|c|c|}
\hline Variable & $\begin{array}{c}\text { Endpoint } \\
\text { LD }^{1}\end{array}$ & $\begin{array}{c}\text { \% change } \\
\text { LD }^{2}\end{array}$ & $\begin{array}{c}\text { Endpoint } \\
H D^{1}\end{array}$ & $\begin{array}{c}\text { \% change } \\
H^{2}\end{array}$ \\
\hline Body weight (kg) & $86.2 \pm 8.6$ & $2.1 \pm 1.2$ & $87.0 \pm 8.2$ & $2.4 \pm 1.3$ \\
\hline Waist circumference $(\mathrm{cm})$ & $100.7 \pm 13.3$ & $1.0 \pm 2.3$ & $98.2 \pm 7.3$ & $1.2 \pm 2.2$ \\
\hline Total body fat (\%) & $45.4 \pm 9.4$ & $1.9 \pm 2.1$ & $45.0 \pm 8.6$ & $2.7 \pm 2.3$ \\
\hline Abdominal fat (\%) & $44.8 \pm 9.02$ & $2.1 \pm 2.62$ & $44.9 \pm 7.82$ & $1.2 \pm 1.53$ \\
\hline Systolic blood pressure $(\mathrm{mm} / \mathrm{Hg})$ & $124.1 \pm 16.2$ & $2.5 \pm 3.2$ & $121.5 \pm 14.6$ & $4.8 \pm 2.5$ \\
\hline Diastolic blood pressure $(\mathrm{mm} / \mathrm{Hg})$ & $78.5 \pm 16.0$ & $0.7 \pm 2.6$ & $76.6 \pm 9.4$ & $2.3 \pm 2.6$ \\
\hline Glucose (mmol/L) & $5.2 \pm 0.7$ & $3.8 \pm 1.5$ & $5.2 \pm 0.7$ & $2.1 \pm 1.9$ \\
\hline Insulin $(\mu \mathrm{U} / \mathrm{mL})$ & $16.2 \pm 3.7$ & $10.0 \pm 3.2$ & $14.8 \pm 2.4^{*}$ & $2.5 \pm 2.2^{¥}$ \\
\hline HOMA-IR & $3.8 \pm 1.3$ & $16.5 \pm 4.6$ & $3.4 \pm 0.9^{*}$ & $5.1 \pm 2.8^{*}$ \\
\hline Total cholesterol (mmol/L) & $5.4 \pm 0.9$ & $1.1 \pm 3.1$ & $5.6 \pm 0.8$ & $3.1 \pm 2.4$ \\
\hline LDL-cholesterol (mmol/L) & $3.3 \pm 0.8$ & $-1.2 \pm 2.1$ & $3.4 \pm 0.8$ & $3.9 \pm 5.1$ \\
\hline HDL-cholesterol (mmol/L) & $1.4 \pm 0.3$ & $4.6 \pm 2.3$ & $1.4 \pm 0.4$ & $8.4 \pm 3.4$ \\
\hline Triglycerides (mmol/L) & $1.8 \pm 0.7$ & $-0.05 \pm 8.7$ & $1.7 \pm 0.6$ & $-3.8 \pm 10.1$ \\
\hline ApoB (mg/dl) & $90.7 \pm 20.1$ & $2.1 \pm 1.8$ & $92.5 \pm 19.6$ & $3.2 \pm 4.5$ \\
\hline ApoE (mg/dl) & $5.4 \pm 0.5$ & $-2.5 \pm 1.1$ & $5.3 \pm 0.8$ & $-4.8 \pm 2.6$ \\
\hline $\operatorname{Lp}(a)(m g / d l)$ & $37.3 \pm 37.9$ & $-9.4 \pm 6.2$ & $48.1 \pm 13.1$ & $-0.05 \pm 7.4$ \\
\hline ApoCll (mg/dl) & $6.5 \pm 1.7$ & $10.1 \pm 3.9$ & $6.2 \pm 1.9$ & $2.6 \pm 3.9$ \\
\hline Metabolic rate (kJ/min) & $2.8 \pm 0.7$ & $1.0 \pm 3.9$ & $2.7 \pm 0.8$ & $4.9 \pm 4.3$ \\
\hline Carbohydrate oxidation ( $\mathrm{g} / \mathrm{min}$ ) & $0.01 \pm 0.04$ & $3.6 \pm 1.7$ & $0.03 \pm 0.05$ & $6.8 \pm 3.2$ \\
\hline Fat oxidation (g/min) & $0.07 \pm 0.02$ & $3.8 \pm 0.02$ & $0.06 \pm 0.02$ & $9.6 \pm 10.9$ \\
\hline
\end{tabular}

${ }^{1}$ Endpoint values adjusted for baseline levels within period; mean $\pm S D ; n=23 L D ; n=23 H D$.

${ }^{2} \%$ change from baseline values were calculated using phase $1, \mathrm{~d}-1$.

${ }^{*} P<0.05$ compared with endpoint LD; ${ }^{¥} P<0.05$ compared with \% change from baseline LD.

cohort studies support long-term dairy consumption in lowering the incidence of type II diabetes and metabolic syndrome [11,35-37].

Alternatively, a recently published 12 -month crossover study examining the cardiometabolic health responses to increased dairy consumption by Crichton et al. [38] did not observe an insulin sensitizing response to HD vs. LD intake. This study was similar to the present study in terms of design (crossover), length (6 month), dairy servings (HD, 4 servings/d vs. LD, $\leq 1$ servings/d), and study population (overweight and obese). However, while our study limited dairy products to low fat milk and yogurt, the study design by Crichton et al. was more inclusive by incorporating low fat flavored milk and yogurt, vanilla custard, and a limited amount (no more than 7 servings/week) of cheese (sliced, cottage, ricotta, cream), ice cream, butter, and margarine. We deliberately utilized milk and yogurt as treatments because these dairy products have reasonably long expiration dates, are easily portable, and can be readily incorporated into the diet. Depending on ingredient composition, formulation, and manufacturing process, dairy products have a broad range of textural and physiochemical properties. These differences greatly influence the bioavailability of dairy-derived nutrients and bioactive compounds and may ultimately affect the magnitude and direction of health responses following their consumption. Although our results suggest that consumption of dairy foods in the form of milk and yogurt may have beneficial cardiometabolic effects, it is difficult to speculate if similar responses would be observed in response to the consumption of other dairy foods. Ivey et al. (2011) [19] recently reported that, compared to milk and cheese, yogurt consumption decreased carotid artery intima-media thickness in elderly women. Thus, studies designed to specifically examine health responses to different whole dairy foods and isolated dairy food bioactive components are clearly warranted.

Numerous milk-derived bioactive compounds may contribute to the insulin-sensitizing effects of dairy including calcium, vitamin $\mathrm{D}$, whole whey protein, and fractionated peptides $[39,40]$. Vitamin D is well recognized in sensitizing insulin responses through multiple purported mechanisms which include regulation of insulin receptor expression and stimulation of insulin release by pancreatic $\beta$-cells $[41,42]$. Although both milk and yogurt products used in the present study were vitamin D fortified as stipulated under Canadian federal law, we 
observed no difference in vitamin D intake between the LD and HD phases, suggesting that the insulin sensitizing response to increased dairy intake was independent of vitamin D consumption. However, as this study was designed as free-living and assessed nutrient intake using food records, it is subject to design limitations including poor dietary recall $[43,44]$. Limitations of dietary recall during the 3-day food record may also be responsible for the tendency $(p=0.1)$ observed in calcium intake between the HD (1222 mg) and LD (1024 mg) groups.

Given that the present study was designed to examine the combined health response to low-fat milk and yogurt whole foods, we cannot partition the effects of the specific dairy foods or identify the particular bioactive component(s) that may be responsible for the protective effects against increased insulin resistance. The vast majority of studies examining the influence of dairy consumption on biomarkers of metabolic syndrome have been conducted with whole dairy foods with very few studies designed to partition the specific health effects of isolated dairy components. One notable exception is a recent study by Palacios et al. (2011) [26] who reported no change in body composition or serum lipids in obese subjects instructed to consume low calorie diets providing $\sim 1200 \mathrm{mg} / \mathrm{d}$ calcium from dairy or calcium supplements.

Concerns have been raised that high dairy consumption may be associated with an increased risk of dyslipidemia and obesity [3]. However, the results of this study lend further support to a growing clinical trial database suggesting that low fat dairy foods can be incorporated into diets without adversely raising blood lipids [38,45-47]. Similarly, there is no clear consensus of the long-term effects of dairy consumption on body weight and body composition, with reports of both increased [48], decreased [49-51], and neutral [52,53] body weight changes following dairy consumption. A recent systematic literature review by Kratz et al. examining 16 studies [54] found little support for the hypothesis that increased dairy fat or high fat dairy food consumption contributes to increased adiposity. Similarly, a metaanalysis from Chen et al. [55] using 29 RCT recently examined the effects of dairy consumption on body weight and body fat mass. Their results suggest that dairy consumption may not be associated with weight gain, but may have a modest effect in facilitating weight loss in energy restricted and short-term $(<1 \mathrm{yr})$ intervention studies. Results from the present 6 month study demonstrate that, under free-living conditions and without energy restriction, long-term low-fat dairy consumption does not alter body weight, body composition or energy expenditure. These results further suggest that the insulin sensitizing effects of dairy consumption are not related to body fat loss or factors that modulate energy metabolism.
There are several limitations to this study. First, it proved difficult to sustain volunteer interest over such a long trial duration and only 23 subjects of the original 39 fully completed each of the study phases $(41 \%$ dropout rate); however, we were able to retain our desired target of 20 subjects. Interestingly, the previously discussed study by Crichton et al. [38] with a similar design to ours also had a high drop-out rate $(49 \%)$, which suggests that future studies involving high dairy consumption may benefit from a parallel arm design. Until a similar study is repeated with a larger study population, our results should be interpreted with caution. Second, although volunteers were given log books to record their daily dairy intake, these records were not reviewed by the study staff until the end of the study, at which point it was determined that they were incomplete. Therefore, the lack of a compliance evaluation and actual dairy intakes are a major limitation of the current study. Third, subjects were provided with dairy products during the HD phase but were not provided with dairy-free foods of comparable macronutrient composition during the LD phase. This could have resulted in differences in food intake and/or macronutrient balance between the two phases beyond the sensitivity of the dietary analysis conducted.

\section{Conclusions}

In conclusion, the current study suggests that under free-living conditions, consumption of 4 servings/d of low-fat dairy milk and yogurt products for 6 months may improve insulin resistance without negatively impacting bodyweight or lipid status. These results require verification from additional long-term studies with appropriate measures to increase subject retention. Future studies should also be designed to further examine the metabolic effects of specific dairy products and/or dairy-derived bioactive components.

\section{Abbreviations}

HD: High dairy; LD: Low dairy.

\section{Competing interests}

The authors declare that they have no competing interests. This study was supported in part by a Science \& Technology International Collaboration (STIC) grant from the Manitoba Department of Innovation, Energy and Mines.

\section{Authors' contributions}

TCR and CPFM analyzed the data and wrote the initial draft manuscript; HM coordinated the intervention trial and sample analysis; RWB conducted the lipid and lipoprotein analysis; CBR designed and coordinated the study. All authors read and approved the final manuscript.

\section{Acknowledgments}

The technical assistance of Quyen Van (University of Manitoba) and Amy Raslawsky and Marie-Lou Bodziac (University at Buffalo) are greatly appreciated. The authors also wish to acknowledge Aliments UTLIMA Foods Inc. / Yoplait, Granby, QC for supplying the yogurt for the study 


\section{Author details}

'Department of Exercise and Nutrition Sciences, School of Public Health and Health Professions, University at Buffalo, Buffalo, New York 14214, USA. ${ }^{2}$ The Richardson Centre for Functional Foods and Nutraceuticals, University of Manitoba, Winnipeg, Manitoba R3T 2N2, Canada. ${ }^{3}$ Biotechnical and Clinical Laboratory Sciences, University at Buffalo, Buffalo, NY 14214, USA.

Received: 9 January 2013 Accepted: 18 April 2013

Published: 2 May 2013

\section{References}

1. Cordain L, Eaton SB, Sebastian A, Mann N, Lindeberg S, Watkins BA, O'Keefe $\mathrm{JH}$, Brand-Miller J: Origins and evolution of the Western diet: health implications for the 21st century. Am J Clin Nutr 2005, 81(2):341-354.

2. Pfeuffer $M$, Schrezenmeir J: Milk and the metabolic syndrome. Obes Rev 2007, 8(2):109-118.

3. Melnik BC: Milk-the promoter of chronic Western diseases. Med Hypotheses 2009, 72(6):631-639.

4. Wylie-Rosett J: Dairy products and metabolic risk factors: how much do we know? Diabetes Care 2011, 34(4):1064-1065.

5. Zemel MB, Richards J, Mathis S, Milstead A, Gebhardt L, Silva E: Dairy augmentation of total and central fat loss in obese subjects. Int $J$ Obes (Lond) 2005, 29(4):391-397.

6. Stancliffe RA, Thorpe T, Zemel MB: Dairy attentuates oxidative and inflammatory stress in metabolic syndrome. Am J Clin Nutr 2011, 94(2):422-430.

7. Snijder MB, van der Heijden AA, van Dam RM, Stehouwer CD, Hiddink GJ, Nijpels G, Heine RJ, Bouter LM, Dekker JM: Is higher dairy consumption associated with lower body weight and fewer metabolic disturbances? The Hoorn Study. Am J Clin Nutr 2007, 85(4):989-995.

8. Pal S, Ellis V: The chronic effects of whey proteins on blood pressure, vascular function, and inflammatory markers in overweight individuals. Obesity (Silver Spring) 2010, 18(7):1354-1359.

9. Choi HK, Willett WC, Stampfer MJ, Rimm E, Hu FB: Dairy consumption and risk of type 2 diabetes mellitus in men: a prospective study. Arch Intern Med 2005, 165(9):997-1003.

10. Malik VS, Sun Q, van Dam RM, Rimm EB, Willett WC, Rosner B, Hu FB: Adolescent dairy product consumption and risk of type 2 diabetes in middle-aged women. Am J Clin Nutr 2011, 94(3):854-861.

11. Tong X, Dong JY, Wu ZW, Li W, Qin LQ: Dairy consumption and risk of type 2 diabetes mellitus: a meta-analysis of cohort studies. Eur J Clin Nutr 2011, 65(9):1027-1031.

12. Liu S, Choi HK, Ford E, Song Y, Klevak A, Buring JE, Manson JE: A prospective study of dairy intake and the risk of type 2 diabetes in women. Diabetes Care 2006, 29(7):1579-1584.

13. Ruidavets JB, Bongard V, Dallongeville J, Arveiler D, Ducimetiere P, Perret B, Simon C, Amouyel P, Ferrieres J: High consumptions of grain, fish, dairy products and combinations of these are associated with a low prevalence of metabolic syndrome. J Epidemiol Community Health 2007, 61(9):810-817.

14. Melnik BC: Milk signalling in the pathogenesis of type 2 diabetes. Med Hypotheses 2011, 76(4):553-559.

15. Nestel PJ: Effects of dairy fats within different foods on plasma lipids. J Am Coll Nutr 2008, 27(6):735S-740S.

16. Noakes M, Nestel PJ, Clifton PM: Modifying the fatty acid profile of dairy products through feedlot technology lowers plasma cholesterol of humans consuming the products. Am J Clin Nutr 1996, 63(1):42-46.

17. Biong AS, Muller H, Seljeflot I, Veierod MB, Pedersen Jl: A comparison of the effects of cheese and butter on serum lipids, haemostatic variables and homocysteine. Br J Nutr 2004, 92(5):791-797.

18. Rideout TC: Getting personal: considering variable interindividual responsiveness to dietary lipid-lowering therapies. Curr Opin Lipido/ 2011, 22(1):37-42

19. Ivey KL, Lewis JR, Hodgson JM, Zhu K, Dhaliwal SS, Thompson PL, Prince RL: Association between yogurt, milk, and cheese consumption and common carotid artery intima-media thickness and cardiovascular disease risk factors in elderly women. Am J Clin Nutr 2011, 94(1):234-239.

20. Abargouei AS, Janghorbani $M$, Salehi-Marzijarani M, Esmaillzadeh A: Effect of dairy consumption on weight and body composition in adults: a systematic review and meta-analysis of randomized controlled clinical trials. Int J Obes (Lond) 2012, 36(12):1485-1493.
21. Garriguet D: Canadians' eating habits. Health Reports. Statistics Canada, Catalogue 2007, 82-003(18-2):17-32.

22. Marinangeli $C P$, Jones $P J$ : Chronic intake of fractionated yellow pea flour reduces postprandial energy expenditure and carbohydrate oxidation. $J$ Med Food 2011, 14(12):1654-1662

23. Jequier $E$, Acheson $K$, Schutz Y: Assessment of energy expenditure and fuel utilization in man. Annu Rev Nutr 1987, 7:187-208.

24. Schutz $Y$ : The basis of direct and indirect calorimetry and their potentials. Diabetes Metab Rev 1995, 11(4):383-408.

25. Matthews DR, Hosker JP, Rudenski AS, Naylor BA, Treacher DF, Turner RC: Homeostasis model assessment: insulin resistance and beta-cell function from fasting plasma glucose and insulin concentrations in man. Diabetologia 1985, 28(7):412-419.

26. Palacios C, Bertran JJ, Rios RE, Soltero S: No effects of low and high consumption of dairy products and calcium supplements on body composition and serum lipids in Puerto Rican obese adults. Nutrition 2011, 27(5):520-525.

27. Rideout TC, Chan YM, Harding SV, Jones PJ: Low and moderate-fat plant sterol fortified soymilk in modulation of plasma lipids and cholesterol kinetics in subjects with normal to high cholesterol concentrations: report on two randomized crossover studies. Lipids Health Dis 2009, 8:45

28. Folsom AR, Rasmussen ML, Chambless LE, Howard G, Cooper LS, Schmidt $\mathrm{Ml}$, Heiss G: Prospective associations of fasting insulin, body fat distribution, and diabetes with risk of ischemic stroke. The Atherosclerosis Risk in Communities (ARIC) Study Investigators. Diabetes Care 1999, 22(7):1077-1083

29. Fontbonne A, Tchobroutsky G, Eschwege E, Richards JL, Claude JR, Rosselin GE: Coronary heart disease mortality risk: plasma insulin level is a more sensitive marker than hypertension or abnormal glucose tolerance in overweight males. The Paris Prospective Study. Int J Obes 1988, 12(6):557-565

30. Onat A, Ceyhan K, Sansoy V, Basar O, Erer B, Uysal O, Hergenc G: Fasting insulin levels independently associated with coronary heart disease in non-diabetic Turkish men and women. Int J Cardiol 2002, 86(1):61-69.

31. Bonora E, Kiechl S, Willeit J, Oberhollenzer F, Egger G, Meigs JB, Bonadonna $\mathrm{RC}$, Muggeo M: Insulin resistance as estimated by homeostasis model assessment predicts incident symptomatic cardiovascular disease in caucasian subjects from the general population: the Bruneck study. Diabetes Care 2007, 30(2):318-324.

32. Tenenbaum A, Adler Y, Boyko V, Tenenbaum H, Fisman EZ, Tanne D, Lapidot M, Schwammenthal E, Feinberg MS, Matas Z, Motro M, Behar S: Insulin resistance is associated with increased risk of major cardiovascular events in patients with preexisting coronary artery disease. Am Heart J 2007, 153(4):559-565.

33. Bonora E, Formentini G, Calcaterra F, Lombardi S, Marini F, Zenari L, Saggiani F, Poli M, Perbellini S, Raffaelli A, Cacciatori V, Santi L, Targher G, Bonadonna R, Muggeo M: HOMA-estimated insulin resistance is an independent predictor of cardiovascular disease in type 2 diabetic subjects: prospective data from the Verona Diabetes Complications Study. Diabetes Care 2002, 25(7):1135-1141.

34. Nikooyeh B, Neyestani TR, Farvid M, Alavi-Majd H, Houshiarrad A, Kalayi A, Shariatzadeh N, Gharavi A, Heravifard S, Tayebinejad N, Salekzamani S, Zahedirad M: Daily consumption of vitamin D- or vitamin D + calciumfortified yogurt drink improved glycemic control in patients with type 2 diabetes: a randomized clinical trial. Am J Clin Nutr 2011, 93(4):764-771.

35. Fumeron F, Lamri A, Abi Khalil C, Jaziri R, Porchay-Balderelli I, Lantieri O, Vol S, Balkau B, Marre M: Dairy consumption and the incidence of hyperglycemia and the metabolic syndrome: results from a french prospective study, Data from the Epidemiological Study on the Insulin Resistance Syndrome (DESIR). Diabetes Care 2011, 34(4):813-817.

36. Liu S, Song Y, Ford ES, Manson JE, Buring JE, Ridker PM: Dietary calcium, vitamin $D$, and the prevalence of metabolic syndrome in middle-aged and older U.S. women. Diabetes Care 2005, 28(12):2926-2932.

37. Pereira MA, Jacobs DR Jr, Van Horn L, Slattery ML, Kartashov Al, Ludwig DS: Dairy consumption, obesity, and the insulin resistance syndrome in young adults: the CARDIA Study. JAMA 2002, 287(16):2081-2089.

38. Crichton GE, Howe PR, Buckley JD, Coates AM, Murphy KJ: Dairy consumption and cardiometabolic health: outcomes of a 12-month crossover trial. Nutr Metab (Lond) 2012, 9(1):19.

39. Tremblay A, Gilbert JA: Milk products, insulin resistance syndrome and type 2 diabetes. J Am Coll Nutr 2009, 28(Suppl 1):91S-102S. 
40. Perrone F, Da-Silva-Filho AC, Adorno IF, Anabuki NT, Leal FS, Colombo T, Da Silva BD, Dock-Nascimento DB, Damiao A, De Aguilar-Nascimento JE: Effects of preoperative feeding with a whey protein plus carbohydrate drink on the acute phase response and insulin resistance. A randomized trial. Nutr J 2011, 10:66.

41. Maestro B, Campion J, Davila N, Calle C: Stimulation by 1,25dihydroxyvitamin D3 of insulin receptor expression and insulin responsiveness for glucose transport in U-937 human promonocytic cells. Endocr J 2000, 47(4):383-391.

42. Borissova AM, Tankova T, Kirilov G, Dakovska L, Kovacheva R: The effect of vitamin D3 on insulin secretion and peripheral insulin sensitivity in type 2 diabetic patients. Int J Clin Pract 2003, 57(4):258-261.

43. AbuMweis SS, Jew S, Jones PJ: Optimizing clinical trial design for assessing the efficacy of functional foods. Nutr Rev 2010, 68(8):485-499.

44. Schoeller DA: Limitations in the assessment of dietary energy intake by self-report. Metabolism 1995, 44(2 Suppl 2):18-22.

45. Daly RM, Nowson CA: Long-term effect of calcium-vitamin $D(3)$ fortified milk on blood pressure and serum lipid concentrations in healthy older men. Eur J Clin Nutr 2009, 63(8):993-1000.

46. Campbell CG, Brown BD, Dufner D, Thorland WG: Effects of soy or milk protein during a high-fat feeding challenge on oxidative stress, inflammation, and lipids in healthy men. Lipids 2006, 41(3):257-265.

47. Beavers KM, Serra MC, Beavers DP, Hudson GM, Willoughby DS: The lipid-lowering effects of 4 weeks of daily soymilk or dairy milk ingestion in a postmenopausal female population. J Med Food 2010, 13(3):650-656.

48. Snijder MB, van Dam RM, Stehouwer CD, Hiddink GJ, Heine RJ, Dekker JM: A prospective study of dairy consumption in relation to changes in metabolic risk factors: the Hoorn Study. Obesity (Silver Spring) 2008, 16(3):706-709.

49. Zemel MB, Richards J, Milstead A, Campbell P: Effects of calcium and dairy on body composition and weight loss in African-American adults. Obes Res 2005, 13(7):1218-1225.

50. Josse AR, Atkinson SA, Tarnopolsky MA, Phillips SM: Increased consumption of dairy foods and protein during diet- and exercise-induced weight loss promotes fat mass loss and lean mass gain in overweight and obese premenopausal women. J Nutr 2011, 141(9):1626-1634.

51. Champagne CM, Broyles ST, Moran LD, Cash KC, Levy EJ, Lin PH, Batch BC, Lien LF, Funk KL, Dalcin A, Loria C, Myers VH: Dietary intakes associated with successful weight loss and maintenance during the Weight Loss Maintenance trial. J Am Diet Assoc 2011, 111(12):1826-1835.

52. Zemel MB, Sun $X$, Sobhani T, Wilson B: Effects of dairy compared with soy on oxidative and inflammatory stress in overweight and obese subjects. Am J Clin Nutr 2010, 91(1):16-22.

53. Wennersberg MH, Smedman A, Turpeinen AM, Retterstol K, Tengblad S, Lipre E, Aro A, Mutanen P, Seljeflot I, Basu S, Pedersen JI, Mutanen M, Vessby B: Dairy products and metabolic effects in overweight men and women: results from a 6-mo intervention study. Am J Clin Nutr 2009, 90(4):960-968

54. Kratz M, Baars T, Guyenet S: The relationship between high-fat dairy consumption and obesity, cardiovascular, and metabolic disease. Eur J Nutr 2013, 52(1):1-24.

55. Chen M, Pan A, Malik VS, Hu FB: Effects of dairy intake on body weight and fat: a meta-analysis of randomized controlled trials. Am J Clin Nutr 2012, 96(4):735-747

\section{Submit your next manuscript to BioMed Central and take full advantage of:}

- Convenient online submission

- Thorough peer review

- No space constraints or color figure charges

- Immediate publication on acceptance

- Inclusion in PubMed, CAS, Scopus and Google Scholar

- Research which is freely available for redistribution

Submit your manuscript at www.biomedcentral.com/submit
C Biomed Central 